\title{
Study on Lifestyle Intervention and Impaired Glucose Tolerance Maastricht (SLIM): preliminary results after one year
}

Citation for published version (APA):

Mensink, M. R., Feskens, E., Saris, W. H. M., de Bruin, T. W. A., \& Blaak, E. E. (2003). Study on Lifestyle Intervention and Impaired Glucose Tolerance Maastricht (SLIM): preliminary results after one year. International Journal of Obesity, 27(3), 377-384. https://doi.org/10.1038/sj.ijo.0802249

Document status and date:

Published: 01/01/2003

DOI:

10.1038/sj.ijo.0802249

Document Version:

Publisher's PDF, also known as Version of record

\section{Please check the document version of this publication:}

- A submitted manuscript is the version of the article upon submission and before peer-review. There can be important differences between the submitted version and the official published version of record. People interested in the research are advised to contact the author for the final version of the publication, or visit the DOI to the publisher's website.

- The final author version and the galley proof are versions of the publication after peer review.

- The final published version features the final layout of the paper including the volume, issue and page numbers.

Link to publication

\footnotetext{
General rights rights.

- You may freely distribute the URL identifying the publication in the public portal. please follow below link for the End User Agreement:

www.umlib.nl/taverne-license

Take down policy

If you believe that this document breaches copyright please contact us at:

repository@maastrichtuniversity.nl

providing details and we will investigate your claim.
}

Copyright and moral rights for the publications made accessible in the public portal are retained by the authors and/or other copyright owners and it is a condition of accessing publications that users recognise and abide by the legal requirements associated with these

- Users may download and print one copy of any publication from the public portal for the purpose of private study or research.

- You may not further distribute the material or use it for any profit-making activity or commercial gain

If the publication is distributed under the terms of Article $25 \mathrm{fa}$ of the Dutch Copyright Act, indicated by the "Taverne" license above, 


\title{
Study on Lifestyle Intervention and Impaired Glucose Tolerance Maastricht (SLIM): preliminary results after one year
}

\author{
M Mensink ${ }^{1 * *}$, EJM Feskens ${ }^{2}$, WHM Saris ${ }^{1}$, TWA de Bruin ${ }^{3}$ and EE Blaak ${ }^{1}$ \\ ${ }^{1}$ Department of Human Biology, Nutrition and Toxicology Research Institute Maastricht, NUTRIM, Maastricht University, \\ Maastricht, The Netherlands; ${ }^{2}$ Department of Health and Nutrition, National Institute for Public Health and the Environment, \\ Bilthoven, The Netherlands, and ${ }^{3}$ Department of Medicine and Endocrinology, University Hospital Maastricht, Maastricht, The \\ Netherlands
}

\begin{abstract}
AIMS: Important risk factors for the progression from impaired glucose tolerance to type II diabetes mellitus are obesity, diet and physical inactivity. The aim of this study is to evaluate the effect of a lifestyle-intervention programme on glucose tolerance in Dutch subjects with impaired glucose tolerance (ICT).

METHODS: A total of 102 subjects were studied, randomised into two groups. Subjects in the intervention group received regular dietary advice, and were stimulated to lose weight and to increase their physical activity. The control group received only brief information about the beneficial effects of a healthy diet and increased physical activity. Before and after the first year, glucose tolerance was measured and several other measurements were done.

RESULTS: Body weight loss after $1 \mathrm{y}$ was higher in the intervention group. The 2-h blood glucose concentration decreased $0.8 \pm 0.3 \mathrm{mmol} / \mathrm{l}$ in the intervention group and increased $0.2 \pm 0.3 \mathrm{mmol} / \mathrm{l}$ in the control group $(P<0.05)$. Body weight loss and increased physical fitness were the most important determinants of improved glucose tolerance and insulin sensitivity.

CONCLUSION: A lifestyle-intervention programme according to general recommendations is effective and induces beneficial changes in lifestyle, which improve glucose tolerance in subjects with IGT. Body weight loss and increased physical fitness were the most important determinants of improved glucose tolerance and insulin sensitivity.
\end{abstract}

International Journal of Obesity (2003) 27, 377-384. doi:10.1038/sj.ijo.802249

Keywords: impaired glucose tolerance; type II diabetes mellitus; lifestyle intervention; diet; physical activity

\section{Introduction}

A cumulative incidence of progression to diabetes ranging from 23 to $63 \%$ is reported among subjects with impaired glucose tolerance (IGT) followed for $2 \mathrm{y}$ up to $27 \mathrm{y}{ }^{1}$ The blood glucose concentration $2 \mathrm{~h}$ after an oral glucose load is an important predictor of progression to type II diabetes mellitus. ${ }^{1,2}$ Therefore, subjects with IGT are an important target group for the prevention of type II diabetes mellitus and cardiovascular disease.

Several studies have examined the effect of interventions on the progression from IGT to diabetes. Strategies used were

\footnotetext{
*Correspondence: Dr M Mensink, Department of Human Biology, Nutrition and Toxicology Research Institute Maastricht (NUTRIM), Maastricht University, PO Box 616, 6200 MD Maastricht, The Netherlands.

E-mail: m.mensink@hb.unimaas.nl

Received 26 April 2002; revised 17 September 2002;

accepted 11 November 2002
}

drug and/or diet interventions, ${ }^{3,4}$ diet and/or exercise, ${ }^{5}$ or the combination of diet and exercise, often referred to as a lifestyle intervention. ${ }^{6-9}$ The Malmö study ${ }^{6}$ showed the feasibility of such a lifestyle-intervention programme, achieving substantial metabolic improvement after $6 \mathrm{y}$ of a combined diet and physical exercise intervention in men with IGT and early-stage type II diabetes mellitus. Unfortunately, only men were participating in this study and subjects were not randomised to one of the intervention modalities.

The first large, well-controlled, long-term intervention study assessing the impact of lifestyle changes on the progression from IGT to type II diabetes mellitus was the Finish Diabetes Prevention Study (DPS), ${ }^{8}$ The risk of diabetes was reduced by $58 \%$ in the intervention group after a mean duration of follow-up of $3.2 \mathrm{y}$, and the reduction in incidence was directly associated with changes in lifestyle. The Diabetes Prevention Program (DPP) in the United States, a clinical trial designed to evaluate the safety and efficacy of 
interventions that may delay or prevent development of diabetes in people at increased risk for type II diabetes mellitus, shows a comparable reduction in the incidence of diabetes. ${ }^{9}$ Lifestyle changes and treatment with metformin both reduced the incidence of diabetes; however, the lifestyle intervention was twice as effective as metformin in reducing the incidence of diabetes. ${ }^{9}$

To develop and implement intervention programmes, it would be useful to assess the relative importance of changes in several lifestyle factors, that is, dietary intake, body weight and physical activity, on changes in glucose tolerance and the incidence of diabetes. The Chinese Da Qing IGT and Diabetes Study did try to assess the effect of diet alone, exercise alone or the combination of diet and exercise on the development of diabetes. ${ }^{5}$ All intervention modalities led to a significant decrease in the incidence of diabetes; proportional hazard analysis suggested that exercise and the combination of diet and exercise were associated with a larger risk reduction than diet alone. However, firm conclusions cannot be drawn from the latter study because there are concerns about the generalisability of these results to other populations.

The Study on Lifestyle-intervention and Impaired Glucose Tolerance Maastricht (SLIM) is a 3-yr intervention study carried out to evaluate the effect of lifestyle-intervention programme on glucose tolerance and insulin resistance in subjects at risk for developing type II diabetes mellitus. The aim of this paper is to evaluate the effect of this programme after the first year. Secondly, we aim to identify which lifestyle or anthropometric factors are most strongly related to changes in glucose tolerance and insulin resistance.

\section{Material and methods \\ Study design and subjects}

SLIM, is designed to study whether a diet/physical activity intervention programme can improve glucose tolerance in subjects with a risk of developing type II diabetes mellitus. The total study duration is $3 y$.

Recruitment of subjects. The recruitment period started in March 1999. Subjects with a risk for glucose intolerance, that is, those of age $>40 \mathrm{y}$ and a family history of diabetes or a body mass index (BMI) $\geq 25 \mathrm{~kg} / \mathrm{m}^{2}$, were selected from an existing cohort ${ }^{10}$ and invited to undergo a first capillary oral glucose tolerance test (OGTT). Subjects with known or overt diabetes were excluded.

Subjects with an elevated 2-h blood glucose concentration were invited to undergo a second OGTT. For definitive inclusion in the study, mean 2 -h glucose concentration of both OGTTs had to be between 7.8 and $12.5 \mathrm{mmol} / \mathrm{l}$, together with a nondiabetic fasting glucose concentration, that is, less than $7.8 \mathrm{mmol} / \mathrm{l}$. Furthermore, subjects were excluded according to the following criteria: previously diagnosed diabetes mellitus, other than gestational diabetes mellitus; medication use known to interfere with glucose tolerance (eg chronic steroid use); participation in regular vigorous exercise or an intensive weight reduction programme during the last year before the start of the study; and any (chronic) disease that makes participation in a lifestyleintervention program impossible, or has an improbable 5-y survival.

After the recruitment, subjects were randomised to one of the two study groups, the intervention group or the control group. Randomisation was carried out with stratification for sex and mean 2-h plasma glucose concentration. The Medical Ethical Review Committee of Maastricht University approved the study protocol, and all subjects gave their written informed consent before the start of the study.

Altogether, 175 subjects were recruited from the first screening OGTT and invited to undergo a second OGTT. After the second OGTT, 114 subjects (64 men and 50 women) were eligible for the study and have been randomised to one of the two study groups.

\section{Lifestyle-intervention programme}

Intervention group. The intervention programme consists of a dietary and physical activity part, with visits scheduled at regular intervals throughout the study.

Dietary recommendations were based on the Dutch guidelines for a healthy diet (Dutch Nutrition Council) and consisted of: carbohydrate intake of at least $55 \%$ of total energy intake (energy\%); total fat intake of less than 30-35 energy\%, with less than 10 energy $\%$ intake of saturated fatty acids (SAFAs); a cholesterol intake of less than $33 \mathrm{mg} / \mathrm{MJ}$; and protein intake of 10-15 energy\% and an intake of dietary fibre of at least $3 \mathrm{~g} / \mathrm{MJ}$. A weight-loss of $5-10 \%$ during the first year, depending on the degree of obesity, was initially aimed at. No very low-calorie diets (VLCDs) or other weightloss agents were used throughout the study. Furthermore, participants were encouraged to stop smoking and, if necessary, to reduce alcohol intake. Dietary advice was given by a skilled dietitian on an individual basis after consideration of the individual 3-day food record. The first visit was 46 weeks after randomisation, to enable assessment of dietary intake as recorded in the baseline 3-day food record. A second visit followed at 3 months. Thereafter, every 3 months a visit was scheduled. An important goal in the dietary intervention was to reduce saturated fat intake, which was discussed at every visit. At the end of every visit, goals were set for the next visit, like 'replacing high-fat cheese by low-fat cheese' or 'using (olive) oil instead of butter during meal preparing'. For the visit at 9 months, a group session was scheduled instead of an individual visit.

Subjects were stimulated to increase their physical activity to at least $30 \mathrm{~min}$ of moderate physical activity a day for at least 5 days a week, a recommendation made by the American College of Sports Medicine. ${ }^{11}$ At the start of the study, the individual amount of physical activity was 
discussed with a physician. Individual advice was given as to how to increase daily physical activity (walking, cycling and swimming) and goals were set. During every visit with the dietitian physical activity goals were evaluated, and if necessary, new goals were set. Furthermore, subjects were encouraged to participate in an exercise program, specially designed for this study, consisting of components of aerobic exercise training and components of resistance training. Exercise sessions were supervised by trainers used to working with a group of middle-aged people. Subjects had free access to these training sessions, and were stimulated to participate at least $1 \mathrm{~h}$ a week. Intensity of the exercise program was monitored several times and the degree of participation of each individual was recorded by the trainer.

Control group. Subjects in the control group were informed about the beneficial effects of a healthy diet, weight loss and increased physical activity, whereas no individual advice or programmes were provided. Furthermore, each subject received brief written information about the benefits of a healthy diet and increased physical activity. No additional appointments were scheduled, apart from the visit after $1 \mathrm{y}$ for the annual measurements.

\section{Measurements}

Glucose tolerance testing. To follow changes in glucose tolerance during the study a standard OGTT with venous blood sampling was performed at the start of the study and at year 1 . After an overnight fast, subjects reported to the laboratory by car or by bus; fasting blood samples were drawn, and subjects received the glucose load $75 \mathrm{~g}$ glucose, dissolved in $250 \mathrm{ml}$ water, AVEBE, The Netherlands). After $30 \mathrm{~min}, 1$ - and 2-h blood samples were drawn for the determination of the blood glucose concentration.

Laboratory assessments. Plasma glucose concentration was measured with a standard enzymatic technique automated on the Cobas Fara centrifugal analyser (Glucose HK 125, ABX diagnostics, Montpellier, France). Plasma insulin concentrațion was measured with an ELISA assay (Mercodia, Uppsala, Sweden), which shows no crossreactivity with proinsulin. Glycated haemoglobin $\left(\mathrm{HbA}_{1 \mathrm{c}}\right)$ was determined in a fasting plasma sample with the HPLC technique (reference value for our laboratory 4.4-6.2\%). Fasting plasma glucose and insulin concentration were used to calculate an index for insulin resistance with the homeostasis model assessment (HOMA index) described by Matthews et $a .^{12}$ As an indicator for insulin secretion the insulinogenic index $30^{\prime}$ was used (Insulin30-insulin0)/(glucose30-glucose0). ${ }^{13}$

Anthropometry. Anthropometric measurements were performed at the start of the study and after $1 \mathrm{y}$. Body weight was measured with an electronical scale to the nearest $0.1 \mathrm{~kg}$, with the subject wearing only light clothing. Height was measured to the nearest $0.5 \mathrm{~cm}$ with the subject standing on the floor without shoes with the back straight against the wall. BMI was calculated as the ratio of the weight and height squared $\left(\mathrm{kg} / \mathrm{m}^{2}\right)$. Body composition was measured using bioimpedance equipment (Hydra, Xitron Utilities, San Diego, USA). Owing to technical difficulties, BIA was performed in 69 subjects ( 31 INT and $38 \mathrm{CON}$ ). Waist circumference (waist) was measured with the subject in standing position at the level midway between the lowest rib and the iliac crest to the nearest $0.5 \mathrm{~cm}$ and hip circumference was measured as the maximum circumference over the buttocks to the nearest $0.5 \mathrm{~cm}$. Waist-to-hip ratio (WHR) was computed as the ratio between waist and hip circumference. Sagittal and transverse abdominal diameter were measured with the subject in a recumbent position, at the level of the crista iliaca to the nearest millimetre using a sliding beam calliper.

Maximal aerobic capacity. An incremental exhaustive exercise test was performed on an electronically braked bicycle ergometer (Lode Excalibur, Groningen, The Netherlands) to determine the maximal power output $\left(W_{\max }\right.$ ) and maximal peak oxygen consumption $\left(V_{2} \mathrm{O}_{2 \mathrm{max}}\right)$. The test started at a workload of $0.75 \mathrm{~W} / \mathrm{kg}$ fat-free mass (FFM) for $3 \mathrm{~min}$, followed by $3 \mathrm{~min}$ at $1.5 \mathrm{~W} / \mathrm{kg}$ FFM. Subsequently, the workload was increased every $3 \mathrm{~min}$ by $0.5 \mathrm{~W} / \mathrm{kg}$ FFM until exhaustion; that is, subjects were no longer able to maintain a pedalling frequency above $60 \mathrm{rpm}$. Throughout the whole experiment, $\mathrm{O}_{2}$ consumption and $\mathrm{CO}_{2}$ production were measured with an Oxycon-Beta (Mijnhard, Breda, The Netherlands) to define maximal peak $V \mathrm{O}_{2}$. Maximal power output was calculated using the time spent on the last workload until exhaustion.

Other measurements. Before the start of the study and at the visit after $1 \mathrm{y}$ a medical history was taken and a physical examination was performed, including recording of a 12lead resting ECG. A 3-day food record (two weekdays and one weekend day) was kept at the start of the study and after 1 y. Food records were checked by a dietitian and intake of nutrients was calculated with a computer program using the Dutch food table.

Outcome. In this study, the primary outcome measure is the change in glucose tolerance, defined as the 2-h blood glucose concentration during the OGTT. Secondary outcome measures are changes in fasting plasma glucose concentration, changes in plasma insulin concentration, changes in insulin resistance (as indicated by the HOMA index) and changes in $\mathrm{HbA}_{1}$.

Statistical analysis. Data are expressed as mean \pm s.e.m. Changes after $1 \mathrm{y}$ of intervention are calculated and expressed as mean and their $95 \%$ CI. Differences at baseline, at year 1 and differences in mean changes from baseline to year 1 between groups were analysed with an unpaired $t$-test. A two-tailed paired $t$-test was used to analyse differences 
within groups between baseline and at year 1. Univariate and stepwise regression analyses were performed to identify the contribution of changes in lifestyle and anthropometric factors to changes in glucose tolerance (2-h glucose tolerance) and insulin resistance (HOMA index) in the intervention group. All analyses were performed with Statview 5.0 for Macintosh.

\section{Results}

At the start of the study 114 subjects were randomised to one of the two study groups. During the first year, total dropout was $10 \%$ (twelve subjects). The dropout rate was higher in the intervention group (eight subjects) as compared to the control group (four subjects). Two subjects dropped out for medical reasons (thyroid disease and cancer) and ten subjects for motivational reasons (lack of time, too much effort). Baseline characteristics of the subjects who did leave the study did not differ from the 102 subjects completing the first year (data not shown). In this paper, the results of the 102 subjects still participating in the study after the first year will be presented and discussed.

Table 1 depicts the characteristics of the 102 subjects at baseline. No differences were found in baseline characteristics between the groups. Baseline fasting and 2 -h blood glucose concentrations were 6.0 and $8.8 \mathrm{mmol} / 1$ in the intervention group, and 5.8 and $8.6 \mathrm{mmol} / 1$ in the control group.

Table 1 Subjects characteristics at baseline $(n=102)$

\begin{tabular}{|c|c|c|}
\hline & \multicolumn{2}{|c|}{ Baseline } \\
\hline & Intervention & Control \\
\hline Number (male/female) & $47(27 / 20)$ & $55(31 / 24)$ \\
\hline Age $(y)$ & $55 \pm 1$ & $58 \pm 1$ \\
\hline Body weight $(\mathrm{kg})$ & $86.3 \pm 2.1$ & $83.5 \pm 1.6$ \\
\hline $\mathrm{BMI}\left(\mathrm{kg} / \mathrm{m}^{2}\right)$ & $29.7 \pm 0.5$ & $29.2 \pm 0.5$ \\
\hline Waist $(\mathrm{cm})$ & $102.3 \pm 1.6$ & $102.1 \pm 1.2$ \\
\hline WHR & $0.97 \pm 0.01$ & $0.97 \pm 0.01$ \\
\hline Sagittal abdominal diameter $(\mathrm{mm})$ & $247 \pm 4.7$ & $240 \pm 3.9$ \\
\hline Transverse abdominal diameter (mm) & $376 \pm 5.1$ & $377 \pm 3.8$ \\
\hline$W_{\max }(n=92)(W)$ & $151 \pm 6.3$ & $145 \pm 5.5$ \\
\hline$V O_{2 \max }(n=85)(1 / \mathrm{min})$ & $2.21 \pm 0.09$ & $2.13 \pm 0.08$ \\
\hline Fasting glucose $(\mathrm{mmol} / \mathrm{l})$ & $6.0 \pm 0.1$ & $5.8 \pm 0.1$ \\
\hline $2-h$ glucose $(\mathrm{mmol} / \mathrm{l})$ & $8.8 \pm 0.3$ & $8.6 \pm 0.2$ \\
\hline $\mathrm{HbA1c}(\%)$ & $5.9 \pm 0.1$ & $5.9 \pm 0.1$ \\
\hline Fasting insulin ( $\mathrm{m} \cup / \mathrm{l})$ & $13.7 \pm 1.4$ & $12.3 \pm 0.9$ \\
\hline $2-h$ insulin (mU/l) & $94 \pm 8$ & $89 \pm 9$ \\
\hline HOMA-IR index & $3.75 \pm 0.46$ & $3.24 \pm 0.25$ \\
\hline Insulinogenic index & $14.1 \pm 1.2$ & $18.5 \pm 4.6$ \\
\hline
\end{tabular}

Data are expressed as mean \pm s.e.m.
Reduction in body weight after $1 \mathrm{y}$ was significantly larger in the intervention group as compared to the control group $(P<0.01$, see Table 2$)$. Also, a significant larger decrease in waist circumference and sagittal and transverse abdominal diameter was seen in the intervention group as compared to the control group, whereas changes in WHR did not change in both groups (see Table 2). As measured with bioimpedance, change in fat mass (FM) was significantly different between groups $(-1.2 \pm 0.6 v s+0.5 \pm 0.5 \mathrm{~kg}$ for INT and CON, respectively: $P<0.05 ; n=69)$; change in FFM was not $(-0.6 \pm 0.3 v s-1.0 \pm 0.5 \mathrm{~kg}$ for INT and CON, respectively: $P=\mathrm{NS} ; n=69$ ). The intervention group showed a larger increase in $V \mathrm{O}_{2 \max }$ and $W_{\max }$ compared to the control group $(P<0.05)$. After 1 y, 2-h blood glucose concentration was decreased to $0.8 \mathrm{mmol} / 1$ in the intervention group $(95 \% \mathrm{CI}$ : $-1.3,-0.2)$ compared to an increase of $0.2 \mathrm{mmol} / 1(95 \% \mathrm{CI}$ : $-0.4,+0.8)$ in the control group $(P$-value for differences in change between groups $<0.05$ ). Fasting insulin concentration was $2.5 \mathrm{mU} / 1$ lower after $1 \mathrm{y}$ in the intervention group compared to a slight increase of $0.4 \mathrm{mU} / 1$ in the control group ( $P$-value for difference in change $<0.01$ ). Insulin resistance, as indicated by the HOMA index, decreased in the intervention group and slightly increased in the control group ( $P$-value for difference in change $<0.05$, see Table 2 ). The insulinogenic index, an index of Beta-cell function, did not change in both groups.

Nutrient intake at baseline and after $1 \mathrm{y}$, calculated from the 3 -day food record, is shown in Table 3 . Baseline values for energy intake, macronutrient intake, alcohol consumption and fibre intake were comparable between groups. At the end of year 1 , the intervention group had increased their carbohydrate and fibre intake $(P<0.001)$. Subjects in the intervention group decreased their total fat intake, saturated and monounsaturated fatty acid (MUFA) intake $(P<0.001)$ without changing their polyunsaturated fatty acid (PUFA) intake. Changes in intake of total fat, SAFA, MUFA, carbohydrate and fibres were significantly different between groups $(P<0.05$, See Table 3$)$.

Finally, we analysed the impact of changes in risk factors on changes in glucose tolerance and insulin resistance in the intervention group. In Table 4 , the results of the regression analysis are shown. The change in sagittal abdominal diameter correlated with the change in glucose tolerance $(P<0.05)$. The change in body weight, $\mathrm{BMI}$ and $V \mathrm{O}_{2 \max }$ tended to correlate with the change in glucose tolerance $(P<0.10)$. Forward stepwise regression analysis with body weight, sagittal diameter and $V \mathrm{O}_{2 \max }$ as independent variables revealed that the change in body weight was most strongly related to the change in glucose tolerance $(0.13 \mathrm{mmol} / \mathrm{l} / \mathrm{kg}$ body weight, $P<0.05)$. The same procedure was repeated with the change in HOMA index as a dependent variable (Table 4). Changes in body weight, body composition (waist, WHR and sagittal diameter), aerobic capacity and nutrient intake (total fat and MUFA and SAFA) were related to changes in insulin resistance (all $P<0.05$ ). Stepwise regression with changes in body weight, sagittal 
Table 2 Changes in subjects characteristics from baseline to year 1 for intervention and cantrol group

\begin{tabular}{|c|c|c|c|c|}
\hline \multirow{4}{*}{$\begin{array}{l}\text { Body weight }(\mathrm{kg}) \\
\text { BMI }\left(\mathrm{kg} / \mathrm{m}^{2}\right)\end{array}$} & \multicolumn{2}{|c|}{ Intervention } & \multicolumn{2}{|c|}{ Control } \\
\hline & \multicolumn{2}{|c|}{ (27 men/20 women) } & \multicolumn{2}{|c|}{ (31 men/24 women) } \\
\hline & $-2.7 \pm 0.5$ & $(-3.8 ;-1.6)$ & $-0.2 \pm 0.5$ & $(-1.2 ;+0.8)^{\star \star}$ \\
\hline & $-0.9 \pm 0.2$ & $(-1.3 ;-0.5)$ & $-0.0 \pm 0.2$ & $(-0.4 ;+0.3)^{* *}$ \\
\hline Waist (cm) & $-3.5 \pm 0.5$ & $(-4.6 ;-2.4)$ & $-1.4 \pm 0.6$ & $(-2.6 ;-0.1)^{\star}$ \\
\hline Sagittal abdominal diameter (mm) & $-10.5 \pm 2.8$ & $(-16.1 ;-4.8)$ & $+0.3 \pm 2.4$ & $(-4.5 ;+5.1)^{\star \star}$ \\
\hline Transverse abdominal diameter $(\mathrm{mm})$ & $-8.7 \pm 2.9$ & $(-14.6 ;-2.9)$ & $-0.3 \pm 1.9$ & $(-4.1 ;+3.4)^{*}$ \\
\hline$W_{\max }(n=92)(W)$ & $+2.7 \pm 1.9$ & $(-1.2 ;+6.5)$ & $-3.0 \pm 1.7$ & $(-6.5 ;+0.3)^{\star}$ \\
\hline $\mathrm{VO}_{2 \max }(n=85)(1 / \mathrm{min})$ & $+0.10 \pm 0.03$ & $(+0.04 ;+0.16)$ & $-0.00 \pm 0.03$ & $(-0.06 ;+0.07)^{\star}$ \\
\hline Fasting glucose (mmal/l) & $-0.1 \pm 0.1$ & $(-0.2 ;+0.1)$ & $+0.1 \pm 0.1$ & $(-0.1 ;+0.2)$ \\
\hline 2-h glucose (mmol/l) & $-0.8 \pm 0.3$ & $(-1.3 ;-0.2)$ & $+0.2 \pm 0.3$ & $(-0.4 ;+0.8)^{\star}$ \\
\hline Fasting insulin (mU/l) & $-2.5 \pm 0.9$ & $(-4.2 ;-0.7)$ & $+0.4 \pm 0.6$ & $(-0.8 ;+1.6)^{\star \star}$ \\
\hline $2-h$ insulin $(\mathrm{mu} / \mathrm{l})$ & $-6.7 \pm 7.0$ & $(-20.0 ;+6.5)$ & $+15.1 \pm 10.0$ & $(-5.1 ;+35.2)$ \\
\hline HOMA-IR index & $-0.72 \pm 0.29$ & $(-1.3 ;-0.1)$ & $+0.14 \pm 0.18$ & $(-0.2 ;+0.5)^{*}$ \\
\hline Insulinogenic index & $+1.3 \pm 1.1$ & $(-0.9 ;+3.5)$ & $-2.5 \pm 4.7$ & $(-12.0 ;+6.9)$ \\
\hline
\end{tabular}

Data are expressed as mean \pm s.e.m. $(95 \% \mathrm{Cl})$.

P-value for difference in change between groups: * $<0.05 ;{ }^{* *}<0.01 ; * * * 0.001$.

Table 3 Nutritional intake, as reported in the 3-day food diary, at baseline and at year 1 for intervention and control group

\begin{tabular}{|c|c|c|c|c|c|}
\hline & \multicolumn{2}{|c|}{ Baseline } & \multicolumn{2}{|c|}{$1 y$} & \multirow[t]{2}{*}{ P-value for diff. in change } \\
\hline & Intervention $(n=47)$ & Control $(n=55)$ & Intervention $(n=47)$ & Control $(\mathrm{n}=55)$ & \\
\hline Energy intake (M]/day) & $9.1 \pm 0.4$ & $8.5 \pm 0.3$ & $7.9 \pm 0.3^{* \star *}$ & $8.2 \pm 0.3$ & 0.02 \\
\hline Carbohydrates (energy \%) & $42.2 \pm 1.0$ & $43.2 \pm 0.9$ & $46.9 \pm 1.1^{\star \star \star}$ & $43.9 \pm 1.0$ & $<0.01$ \\
\hline Fat (energy \%) & $36.2 \pm 0.9$ & $35.7 \pm 0.9$ & $31.2 \pm 1.0^{\star \star \star \star}$ & $34.7 \pm 0.8$ & 0.01 \\
\hline SAFA (energy $\%$ ) & $14.0 \pm 0.4$ & $13.9 \pm 0.4$ & $11.2 \pm 0.4^{\star \star *}$ & $13.3 \pm 0.5$ & $<0.01$ \\
\hline MUFA (energy \%) & $12.9 \pm 0.4$ & $12.8 \pm 0.4$ & $10.8 \pm 0.4^{* \star \star}$ & $12.4 \pm 0.4$ & $<0.01$ \\
\hline PUFA (energy \%) & $6.7 \pm 0.4$ & $6.5 \pm 0.3$ & $6.9 \pm 0.4$ & $6.5 \pm 0.3$ & NS \\
\hline Cholesterol (mg/Ml) & $25.7 \pm 1.4$ & $27.5 \pm 1.6$ & $22.5 \pm 1.2$ & $26.1 \pm 1.3$ & NS \\
\hline Protein (energy \%) & $15.7 \pm 0.4$ & $16.0 \pm 0.4$ & $17.4 \pm 0.5^{\star \star *}$ & $16.3 \pm 0.5$ & 0.06 \\
\hline Alcohol (energy \%) & $5.9 \pm 1.1$ & $5.1 \pm 0.7$ & $4.5 \pm 0.9$ & $5.1 \pm 0.8$ & NS \\
\hline Fibre $(g / M)$ & $2.8 \pm 0.1$ & $2.6 \pm 0.1$ & $3.3 \pm \overline{0.1} 1^{* * *}$ & $2.8 \pm 0.1$ & 0.03 \\
\hline
\end{tabular}

Data are expressed as mean \pm s.e.m.

$P$-value for the difference within groups between $1 y$ and baseline: $* * * 0.001$.

$F A=$ fatty acid; SAFA = saturated fatty acid; MUFA = monounsaturated fatty acid; PUFA = polyunsaturated fatty acid.

diameter, $\mathrm{VO}_{2 \max }$ and fat intake as the independent variable showed that both change in body weight and change in $V \mathrm{O}_{2 \max }$ were related to the change in HOMA index $(P<0.01)$.

\section{Discussion}

SLIM is carried out to evaluate the effect of lifestyle changes on glucose tolerance in subjects at risk for developing type II diabetes mellitus. The 3-y lifestyle-intervention programme consists of a dietary and physical activity part. In this paper the results after $1 y$ of intervention are reported. The main finding is that after $1 \mathrm{y}$ glucose tolerance was significantly improved in the intervention group, with a decrease in the 2$h$ blood glucose concentration of $0.8 \mathrm{mmol} / 1$, which is significantly different from the increase of $0.2 \mathrm{mmol} / \mathrm{l}$ found in the control group.

Several studies have started to evaluate intervention programmes that may delay or prevent the development of type II diabetes mellitus in high-risk subjects. The Finnish DPS was the first well-designed large-scale intervention study clearly showing the impact of lifestyle changes on glucose tolerance and the incidence of diabetes. ${ }^{8}$ After a mean 
Table 4 Results of regression analysis in the intervention group ( $n=47$ ), with the change after 1 y in 2 -h blood glucose concentration (left) and HOMA index (right) as the dependent variable and changes after $1 y$ in several lifestyle and anthropometric factors as the independent variable

\begin{tabular}{|c|c|c|c|c|c|c|c|c|}
\hline & \multicolumn{4}{|c|}{ Chonge in glucose toleronce $(2-h$ blood glucose $)$} & \multicolumn{4}{|c|}{ Change in insulin resistance (HOMA-index) } \\
\hline & \multicolumn{2}{|c|}{ Univariate regression } & \multicolumn{2}{|c|}{ Stepwise regression } & \multicolumn{2}{|c|}{ Univariate regression } & \multicolumn{2}{|c|}{ Stepwise regression } \\
\hline & Coefficient & P-value & Coefficient & P-value & Coefficient & P-value & Coefficient & P-value \\
\hline \multicolumn{9}{|l|}{ Change in } \\
\hline Body weight $(\mathrm{kg})$ & +0.13 & 0.06 & +0.18 & $<0.05$ & +0.25 & $<0.0001$ & +0.20 & $<0.01$ \\
\hline $\mathrm{BMI}\left(\mathrm{kg} / \mathrm{m}^{2}\right)$ & +0.39 & 0.07 & - & - & +0.72 & $<0.0001$ & - & - \\
\hline Waist circumference $(\mathrm{cm})$ & +0.07 & 0.36 & - & - & +0.21 & $<0.0001$ & - & - \\
\hline WHR & +3.35 & 0.69 & - & - & +15.4 & $<0.05$ & - & - \\
\hline Sagittal abdominal diameter $(\mathrm{mm})$ & +0.03 & $<0.05$ & - & - & +0.04 & $<0.0001$ & - & - \\
\hline $\mathrm{VO}_{2 \max }(\mathrm{ml} / \mathrm{min})$ & -0.003 & 0.09 & - & - & -0.005 & $<0.0001$ & -0.003 & $<0.01$ \\
\hline Fat intake (energy\%) & +0.04 & 0.35 & - & - & +0.08 & $<0.01$ & - & - \\
\hline MUFA intake (energy\%) & +0.07 & 0.46 & - & - & +0.16 & $<0.05$ & - & - \\
\hline SAFA intake (energy \%) & +0.09 & 0.22 & - & - & +0.14 & $<0.05$ & - & - \\
\hline Fibre intake $(g / M \mid)$ & -0.25 & 0.48 & - & - & -0.32 & 0.23 & - & - \\
\hline
\end{tabular}

For abbreviations, see Table 3 .

follow-up time of $3.2 \mathrm{y}$, a risk reduction of $58 \%$ was seen in the intervention group. The recently published US Diabetes Prevention Program showed that lifestyle changes and treatment with metformin both reduced the incidence of diabetes. However, the lifestyle intervention was more effective than metformin.?

The results of our study demonstrate once again the importance of lifestyle changes on changes in glucose tolerance. Furthermore, they confirm that a lifestyle intervention works in a different population. This is important since the (long-term) effect of a lifestyle intervention will depend on the underlying food and exercise habits, frequency of obesity and IGT, and the attitude of the participants towards lifestyle-intervention programmes. For example, an important difference between the Finnish DPS, the American DPP and the present study is the degree of obesity in the population studied. Average BMI was $29.5 \mathrm{~kg} /$ $\mathrm{m}^{2}$ in our study ws $31.2 \mathrm{~kg} / \mathrm{m}^{2}$ in the Finnish $\mathrm{DPS}^{8}$ and $33.9 \mathrm{~kg} / \mathrm{m}^{2}$ in the American DPP. ${ }^{9}$ As obesity is known as one of the most important risk factors for the progression of IGT to type II diabetes mellitus, our results indicate that even in a population with a lower degree of obesity a lifestyleintervention programme can substantially improve glucose tolerance. This is in line with the finding from the American DPP that in subgroups with a different degree of obesity, a comparable risk reduction was found with a lifestyle intervention. $^{9}$

The incidence of type II diabetes rises in a graded manner with an increasing 2-h blood glucose concentration, even at levels below the threshold for IGT. ${ }^{1,14}$ Thus, a decrease in 2 -h glucose should lead to a decreased risk of progression to diabetes. In the Finnish DPS, a reduction of $0.9 \mathrm{mmol} / 1$ in the 2-h blood glucose concentration after 1 y gave rise to a risk reduction of $58 \%$ in the incidence of diabetes at the end of the study. ${ }^{8}$ The change in 2 -h blood glucose concentration found in our study after $1 \mathrm{y}$ was of comparable magnitude $(-0.8 \mathrm{mmol} / \mathrm{l})$, indicating a considerable reduction in the risk of progression to type II diabetes mellitus.

In accordance with the results found in earlier studies, 5,8 weight loss was small, but substantial $(-2.7 \mathrm{~kg}$ in the intervention group $v s-0.2 \mathrm{~kg}$ in the control group). This is somewhat less than that found in the DPS ${ }^{8}$ and the DPP. However, as indicated before, our population was less obese $\left(\mathrm{BMI}=29.5 \mathrm{~kg} / \mathrm{m}^{2}\right)$ as compared to the population of the DPS $\left(B M I=31.5 \mathrm{~kg} / \mathrm{m}^{2}\right)$ and the DPP $\left(B M I=33.9 \mathrm{~kg} / \mathrm{m}^{2}\right)$. Weight loss was achieved by dietary advice, based on guidelines for a healthy diet (Dutch Nutrition Council), regular support (every 3 months) and the stimulation to increase the level of physical activity. No severe energy restriction or (very) lowcalorie diet was prescribed, which often results in large amounts of weight-loss with a substantial regain after the dieting period. Weight loss was attributable for one-third to loss of FFM, and two-third to FM. Whether the weight reduction achieved after $1 \mathrm{y}$ can be maintained during the remainder of the study will be seen in the future.

Not only the overall body weight decreased, but also abdominal obesity decreased, as reflected by the decrease in waist circumference and sagittal abdominal diameter. This is important, because abdominal obesity is positively is associated with (prograssion to) type II diabetes mellitus, ${ }^{1}$. No difference in change in the WHR was observed as the reduction in weight in the intervention group resulted in both a reduction in waist and hip circumference. The relative small changes in body weight and abdominal fat accumulation seen in the intervention group after $1 \mathrm{y}$ were accompanied by a substantial improvement in glucose tolerance and a reduction in insulin resistance, as indicated by a decreased HOMA index and fasting insulin concentration. This points out the impact of relative small changes in body weight and abdominal body fat on metabolic improvements. 
Diet and nutrition play an important part in the development of type II diabetes mellitus. Besides total fat and carbohydrate intake, the type of fat and carbohydrate appears to be important. ${ }^{16}$ A higher intake of polyunsaturated fat and possibly long-chain n-3 FAs could be beneficial, whereas a higher intake of SAFAs and trans-FAs could adversely affect glucose metabolism. ${ }^{16}$ After $1 \mathrm{y}$ subjects in the intervention group had successfully exchanged saturated and monounsaturated fat for carbohydrates without changing their polyunsaturated fat intake. Since SAFA may adversely affect glucose metabolism, this exchange could beneficially influence glucose tolerance. Comparable results were found in the KANWU-study, ${ }^{17}$ where reducing SAFA and increasing MUFA intake induced a significant improvement in insulin sensitivity in subjects with a lower fat intake ( $<37$ energy\%). Furthermore, fibre intake was increased in the intervention group. A higher amount of dietary fibre seems to improve glycaemic and insulinaemic responses and lower the risk of type II diabetes mellitus. ${ }^{16}$ When interpreting data on dietary intake, some caution has to be taken into account. Subjects reported their food intake by means of a 3day food record, which give rise to under-reporting, especially in obese subjects. ${ }^{18}$ Furthermore, changes in the intervention group in dietary intake could reflect a more advised dietary change than the actual dietary change.

To develop and implement intervention programmes aiming at the prevention or the delay of the progression from IGT to diabetes, it is useful to assess the importance of changes in several lifestyle factors, that is, dietary intake, body weight and physical activity. Our purpose was not to compare several different intervention strategies with each other, but rather to identify which lifestyle and anthropometric factors (as body weight, visceral adiposity, physical fitness and nutritional intake) were most strongly related with changes in glucose tolerance and insulin resistance. An advantage of the present study was that we were able to relate these factors to changes in glucose tolerance, as well as to changes in insulin resistance (HOMA index). Change in body weight was the most important factor associated with improvement in glucose tolerance and insulin sensitivity in the intervention group. However, besides weight loss there was an additional effect of increased aerobic capacity $\left(\mathrm{VO}_{2 \mathrm{max}}\right)$ on the improvement in insulin resistance. An observation comparable to results of the Malmö study, in which an improvement in glucose tolerance, was correlated to both weight reduction and increased fitness. ${ }^{6}$ This effect of increased aerobic capacity or fitness is not surprising regarding the impact of exercise (training) on insulin sensitivity. ${ }^{19}$

In conclusion, our study shows that a lifestyle-intervention programme according to general recommendations is effective and improves glucose tolerance in subjects with IGT, thereby reducing the risk of progression to type II diabetes. Body weight loss and increased physical fitness were the most important determinants of improved glucose tolerance and insulin sensitivity.

\section{Acknowledgements}

We thank Jos Stegen for all his support during the numerous OGTTs and the analytical measurements. Furthermore, we thank Tanja Hermans-Limpens, Ilse Nijs and Marja van der Hulst for running the dietary intervention and for all their effort to motivate the subjects to participate.

This work was supported by a grant from the Dutch Diabetes Research Foundation (DFN. 98:901) and the Netherlands Organization for Scientific Research Zon MW.990-35-034.

\section{References}

1 Edelstein SL, Knowler WC, Bain RP, Andres R, Barrett-Connor EL, Dowse GK, Haffner SM, Pettitt DJ, Sorkin JD, Muller DC. Predictors of progression from impaired glucose tolerance to NIDDM: an analysis of six prospective studies. Diabetes 1997; 46: $701-710$.

2 de Vegt F, Dekker JM, Jager A, Hienkens E, Kostense PJ, Stehouwer CD, Nijpels G, Bouter LM, Heine RJ. Relation of impaired fasting and postload glucose with incident type 2 diabetes in a Dutch population: The Hoom Study. JAMA 2001; 285: 2109-2113.

3 Sartor G, Schersten B, Carlstrom S, Melander A, Norden A Persson $G$. Ten-year follow-up of subjects with impaired glucose tolerance: prevention of diabetes by tolbutamide and diet regulation. Diabetes 1980; 29: 41-49.

4 Chiasson JL, Gomis R, Hanefeld M, Josse RG, Karasik A, Laakso M. The STOP-NIDDM Trial: an intemational study on the efficacy of an alpha-glucosidase inhibitor to prevent type 2 diabetes in a population with impaired glucose tolerance: rationale, design, and preliminary screening data. Study to Prevent Non-InsulinDependent Diabetes Mellitus. Diabetes Care 1998; 21: 1720-\$725.

5 Pan XR, Li GW, Hu YH, Wang JX, Yang WY, An ZX, Hu ZX, Lin J Xiao $J Z$, Cao $F B$. Effects of diet and exercise in preventing NIDDM in people with impaired glucose tolerance. The Da Qing IGT and Diabetes Study. Diabetes Care 1997; 20: 537-544.

6 Eriksson KF, Lindgärde F. Prevention of type 2 (non-insulindependent) diabetes mellitus by diet and physical exercise. The 6 year Malmö feasibility study. Diabetologia 1991; 34: 891-898.

7 Bourn DM, Mann JI, McSkimming BJ, Waldron MA, Wishart JD. Impaired glucose tolerance and NIDDM: does a lifestyle intervention program have an effect? Diabetes Care 1994; 17: 13111319.

8 Tuomilehto J, Lindstrom J, Eriksson JG, Valle TT, Hamalainen $H_{\text {, }}$ Ilanne-Parikka P, Keinanen-Kiukaanniemi S, Laakso M, Louheranta A, Rastas M. Prevention of type 2 diabetes mellitus by changes in lifestyle among subjects with impaired glucose tolerance. $N$ Engl / Med 2001; 344: 1343-1350.

9 Knowler WC, Barrett-Connor E, Fowler SE, Hamman RF, Lachin JM, Walker EA, Nathan DM. Reduction in the incidence of type 2 diabetes with lifestyle intervention or metformin. $N$ Engl J Med 2002; 346: 393-403

10 van Dam RM, Boer JM, Feskens EJ, Seidell JC. Parental history of diabetes modifies the association between abdominal adiposity and hyperglycemia. Diabetes Care 2001; 24: 1454-1459.

11 American College of Sports Medicine Position Stand. The recommended quantity and quality of exercise for developing and maintaining cardiorespiratory and muscular fitness, and flexibility in healthy adults. Med Sci Sports Exer 1998; 30: 975991.

12 Matthews DR, Hosker JP, Rudenski AS, Naylor BA, Treacher DF, Turner RC. Homeostasis model assessment: insulin resistance and beta-cell function from fasting plasma glucose and insulin concentrations in man. Diabetologia $1985 ; 28 ; 412-419$.

13 Albareda M, Rodriguez-Espinosa J, Murugo M, de Leiva A, Corcoy $\mathrm{R}$. Assessment of insulin sensitivity and beta-cell function from 
measurements in the fasting state and during an oral glucose tolerance test. Diabetologia 2000; 43: 1.507-1511.

14 Saad MF, Knowler WC, Pettitt DJ, Nelson RG, Bennett PH. Transient impaired glucose tolerance in Pima Indians: is it important? BMI 1988; 297: 1438-1441.

15 Seidell JC, Han TS, Feskens EJ, Lean ME. Narrow hips and broad waist circumferences independently contribute to increased risk of non-insulin-dependent diabetes mellitus. I Intern Med 1997; 242: 401-406.

16 Hu FB, van Dam RM, Liu S. Diet and risk of Type II diabetes: the role of types of fat and carbohydrate. Diabetologia 2001; 44: 805-817.
17 Vessby B, Unsitupa $M$, Hermansen $K$, Riccardi $G$, Rivellese $A A$ Tapsell LC, Nalsen C, Berglund L, Louheranta A, Rasmussen BM. Substituting dietary saturated for monounsaturated fat impairs insulin sensitivity in healthy men and women: The KANWU Study. Diabetologia 2001; 44: 312-319.

18 Goris AH, Meijer EP, Westerterp KR. Repeated measurement of habitual food intake increases under-reporting and induces selective under-reporting. Br I Nutr 2001; 85: 629-634.

19 Ivy JL. Role of exercise training in the prevention and treatment of insulin resistance and non-insulin-dependent diabetes mellitus. Sports Med 1997; 24: 321-336. 